\title{
LA HUELGA CAÑERA DE CATSA, CUARENTA AÑOS DESPUÉS: UNA RECONSTRUCCIÓN DE LOS HECHOS A TRAVÉS DE LOS REPORTES DE LA PRENSA ESCRITA
}

\section{THE SUGAR CANE STRIKE OF CATSA, FORTY YEARS AFTER: A RECONSTRUCTION OF THE FACTS THROUGH THE WRITTEN PRESS REPORTS}

\author{
Jorge Marchena Sanabria*
}

\begin{abstract}
Resumen: Las notas de prensa que a continuación se presentan, dan muestra de las contradicciones o, más bien, los controvertidos discursos de corte neoliberal y conservador que llenaron páginas y dominaron el discurso y orientación editorial de los medios de comunicación, en el marco del movimiento de huelga protagonizado por los trabajadores de los ingenios azucareros de la Central Azucarera del Tempisque, Sociedad Anónima (CATSA), durante la década de 1970.
\end{abstract}

Palabras claves: caña de azúcar; movimiento de protesta; fuente histórica; historia; Costa Rica.

\begin{abstract}
The following press notes that are presented below show the contradictions or, rather, the controversial neoliberal and conservative discourses that filled the pages and dominated the discourse and editorial orientation of the media, within the frame of the strike movement carried out by the workers of the sugar mills of the Azucarera del Tempisque, Sociedad Anónima (CATSA), during the 1970's.
\end{abstract}

Keywords: Sugar Cane; Labour Movements; Historical Source; History; Costa Rica.

* Costarricense. Máster en Historia Aplicada con énfasis en Historia del Poder y Control Social, Escuela de Historia, Universidad Nacional (UNA), Heredia, Costa Rica. Docente de la Universidad de Costa Rica (UCR), Sede de Occidente. Colaborador del Centro de Investigaciones en Identidad y Cultura Latinoamericanas (CIICLA). Correo electrónico jorge.marchena@ucr.ac.cr 


\section{Presentación}

En marzo de 1979, a pocos meses de su publicitada y resonante inauguración, una huelga de cortadores de caña de azúcar afectó sensiblemente a la Central Azucarera del Tempisque, Sociedad Anónima (CATSA). Concebida como una de las subsidiarias estelares de la Corporación Costarricense de Desarrollo (CODESA), dicha empresa estatal debía garantizar el abastecimiento interno de azúcar refinado, así como dar paso a una "creciente prosperidad" de la provincia de Guanacaste, y muy especialmente de las poblaciones ubicadas en la cuenca media del río Tempisque. Fuertes cuestionamientos en torno a la cuantía de los fondos requeridos para su instalación, las plagas de ratas, la contaminación de la red hídrica y, sobre todo, el ataque frontal al modelo de Estado Interventor adoptado y propulsado por los gobiernos liberacionistas hacia esos años, malograron las altas expectativas que en un primer momento se tejieron en torno a las posibilidades, beneficios y trascendencia de la nueva empresa.

La huelga que comprendió los meses de marzo-abril de aquel año se constituiría a la larga en una especie de punto de no retorno. Los principales medios de prensa del momento -La Nación, La República y La Prensa Libre- se comprometieron en una cobertura claramente parcializada y aprovecharon los hechos, para cuestionar no solo a CATSA, sino también de paso al expresidente Rodrigo Carazo Odio (1978-1982) y al citado modelo intervencionista de desarrollo.

Cuando se repara solo en la coyuntura, la cobertura noticiosa luce esencialmente como un mero cuestionamiento y ataque circunstancial a políticos y huelguistas, ya que los medios aprovecharon el evento como un tema fetiche que adornó sus titulares y columnas por varias semanas. Empero, considerado en perspectiva de largo plazo, o incluso visto en retrospectiva, la huelga más bien parece el prefacio o puesta en escena de la subsecuente desestructuración del Estado costarricense heredado de la fase de reformismo de los años $1940 \mathrm{y}$ del proyecto político de la Segunda República.

Ya en años anteriores a 1979, se habían dado importantes "conatos" de huelga, como por ejemplo, un episodio conflictivo casi olvidado en la Hacienda Juan Viñas durante los primeros días del mes de julio de 1977 -también cañero...y otros movimientos sociales fuera de la Meseta Central que merecieron una atención periodística limitada o efímera. En modo alguno se puede asumir que la huelga de CATSA fue un conflicto excepcional o único en su género y que hizo diferencia por sí mismo, pues más bien lo que se ensayó en este singular episodio de confrontación, sería replicado en otra huelga acaecida en el Ingenio El Viejo -en 1982- y cabría preguntarse, si tuvo un importante grado de incidencia en las protestas que explotaron en los puertos y zonas bananeras o en los movimientos de protesta acaecidos en los barrios del sur de la capital entre 1982 y $1983 .{ }^{1}$

1 Para más detalles se pueden consultar las siguientes investigaciones: Carlos Hernández Rodríguez, "Desestructuración económica y crisis social. El Pacífico Sur costarricense en el marco de la década perdida”, 
Por lo pronto lo que pareciera claro -y la siguiente documentación abonará a tal línea argumentativa- es que la huelga de CATSA constituye un parteaguas, $\mathrm{y}$ en gran medida un evento propiciatorio que vino a hacer diferencia y dio paso a transformaciones sustanciales en el estilo de desarrollo y las políticas públicas del país. ${ }^{2}$

¿Qué fue lo que originó el conflicto? ¿Cuáles fueron las motivaciones? Es factible que la premura que caracterizó la creación y apertura de la empresa, coligada a los vastos recursos monetarios -en un momento previo a la fuerte devaluación del colón-, provocó que la Central Azucarera careciera de ciertas garantías básicas para sus trabajadores, y esto, sumado a deficiencias de organización interna, así como a las duras condiciones laborales características de las plantaciones de caña, generaron descontento y movieron a que los cortadores se levantaran en procura de aumentos salariales, acceso a equipamiento básico, dispensadores de agua y botiquines, entre otros avituallamientos.

La respuesta de la empresa estatal fue en extremo agresiva y de inmediato sancionó a los manifestantes. Las acusaciones que se hicieron por medio de la prensa escrita señalaban que el sindicato conformado en CATSA era inexistente, prácticamente fantasmagórico, y del todo ilegal, lo que pronto se extendió al resto del movimiento. Los directivos del ingenio, con la venia del gobierno, pronto refrendaron los estereotipos alrededor de este tipo de movimientos que se han perpetuado hasta el presente. De esta forma, aparte de la reiterada ilegalidad, fue señalado que la huelga solo reunía a un diminuto puñado de participantes, y que el grueso de la empresa operaba a casi toda su capacidad, aunque, contradictoriamente, se registraron cuantiosas pérdidas económicas y daños a las plantaciones.

Las acusaciones no cesaron a lo largo de las semanas en que se extendió el movimiento. Titulares y notas referentes a violencia, sabotajes, la exigencia de levantar bloqueos en las carreteras, así como la permanente calificación y denuncia de una pretendida "conspiración comunista", marcaron el rumbo de la huelga; por lo menos en sus principales aristas mediáticas.

Es importante señalar que el Gobierno de la República también evidenció una posición ciertamente ambigua en torno a la huelga. Si en unos momentos se mostró conciliador y presto al diálogo, en otros pasajes de la contienda, varios ministros, hicieron manifiesta una posición intolerante y refractaria contra los

Revista de Historia (Costa Rica) 51-52 (2005): 173-235, URL: http://www.revistas.una.ac.cr/index.php/ historia/article/view/1768; Patricia Alvarenga Venutolo, De vecinos a ciudadanos. Movimientos comunales y luchas cívicas en la historia contemporánea de Costa Rica (San José y Heredia: EUCR; EUNA, 2005) y Sindy Mora Solano, La política de la calle. Organización y autonomía en la Costa Rica contemporánea (San José, Costa Rica: EUCR, 2016).

2 Parteaguas, en el sentido de que los discursos -y estrategias mediáticas- empleados para atacar el movimiento, se utilizarían con tonos y contenidos similares en las siguientes décadas. Asimismo, cabe preguntarse si este fue el momento crucial que marcó un cambio en el tono de las políticas estatales heredadas de las décadas de 1940-1950 y se aceleró el paso hacia un modelo afín al libre mercado y la paulatina contracción de las instituciones públicas. 
manifestantes, exigiendo la disolución inmediata del movimiento y llamando a la aplicación de mano dura, puesto que los huelguistas fueron las más de las veces calificados como peligrosos agitadores. A esto se sumaron los editoriales que condenaron a priori a los trabajadores, sin tomar en consideración los motivos que perseguían.

Los huelguistas no fueron los únicos receptores de este desmedido y furibundo ataque, pues uno de los grandes perdedores fue el mismo presidente Carazo, acusado de ambivalente, y más sintomático aún, los discursos contra CATSA devinieron en diatriba contra el desarrollismo: el intervencionismo había fallado estrepitosamente y era el momento de que la empresa privada se reposicionara y asumiera el liderazgo.

Este, en todo caso, no es el espacio para detallar o reconstruir el proceso que siguió CATSA y que, a finales de la década de 1980, le llevó a convertirse en cooperativa, para luego a mediados del siguiente decenio, ser transferida en su mayor parte a capitales foráneos. ${ }^{3}$ Las notas de prensa que a continuación se presentan dan muestra de las contradicciones o, más bien, los controvertidos discursos de corte neoliberal y conservador que llenaron páginas y dominaron el discurso y orientación editorial de los medios de comunicación.

De antemano, se debe señalar que no fueron seleccionados todos los documentos relacionados con la huelga, solo se anexa una pequeña muestra que resultará más que pintoresca, ya que narra -con un notorio lenguaje coloquial y autorreferencial- no las vicisitudes mismas de la huelga, sino los posicionamientos de la Empresa, parte del discurso del Gobierno de Carazo y la opinión remarcada de los mismos periódicos. Asimismo, los huelguistas y sindicatos trataron de hacerse oír y hacer público su pliego de peticiones; en contra de una "opinión pública" que los había criminalizado sin reparos. Cabe aclarar que muchas notas carecieron de un autor explícito, y lejos de informar o analizar la situación, optaron por verter opiniones conservadoras que consideraban a los trabajadores como infantiles -guiados por una encubierta "mano perversa"- y carentes del derecho de protestar e instando a la policía a emplear las medidas necesarias, es decir, arrestar y frenar el movimiento, aunque se utilizara la violencia.

Por último, no deja de ser llamativo, confrontar este movimiento con los hechos acaecidos en los últimos meses -setiembre y octubre del 2018- que coincidentemente han dado paso a que, de nuevo, se apliquen discursos similares, reiterando el llamado a una férrea intolerancia política y al levantamiento forzado, por la vía policial, de las huelgas.

3 Este proceso fue analizado en: Jorge Marchena Sanabria, "Origen, crisis empresarial y privatización encubierta de la Central Azucarera del Tempisque (CATSA), Guanacaste (1975-1990)”, Revista Rupturas (Costa Rica) 8, n. 1 (2018): 1-39, URL: http://investiga.uned.ac.cr/revistas/index.php/rupturas/article/ view/1972 


\section{- La Nación, "CATSA pide declarar ilegal la huelga de cortadores de caña", 9 de marzo de 1979, 4 A.}

La Central Azucarera Tempisque S.A. (CATSA) planteó ayer ante el Juez de Trabajo de Liberia, la solicitud de ilegalidad para la huelga de cortadores de caña declarada desde anteayer a las 7 a.m., en el ingenio azucarero "Federico Sobrado Carrera", propiedad de dicha empresa.

Por su parte, los trabajadores dialogaron anoche con representantes de CATSA, ante quienes plantearon un pliego de peticiones en el que piden un aumento de salarios, por no menos del 15 por ciento.

El ingenio, según informaron sus funcionarios, deja de producir por cada día inactivo $\notin 450$ mil entre miel y azúcar.

Por otra parte, agregan que están cortadas 2.500 toneladas de caña que, de no ser molidas en el curso de los próximos tres días, se perderán.

Voceros de CATSA, empresa subsidiaria de CODESA, afirmaron que la gente en paro es poca, pero hay un grupo de unos 100 hombres, entre ellos activistas profesionales, que impiden el acceso a quienes sí desean trabajar.

Nuestro informante manifestó: "No hay tal huelga; es un pequeño grupo que, por la fuerza, ha impedido la entrada a los trabajadores".

\section{Protección}

El ingenio de CATSA, a 20 kilómetros al suroeste de Liberia, en el lugar llamado Guardia, y cuya actividad azucarera comenzó el pasado 5 de enero, se encuentra protegido por unos 28 guardias civiles. Entre cortadores de caña, profesionales, obreros especializados y otros, laboran aproximadamente dos mil hombres.

Portavoces de la compañía dijeron que se proyectaba terminar la zafra a mediados de abril, pero que cada día que se prolongue el movimiento, se atrasará la actividad y se corre el riesgo de perder la caña.

Afirmaron que no ha habido comunicación alguna del porqué del paro, y por tanto la huelga ha sido una sorpresa. Investigan las causas para determinar la razón de esa decisión.

\section{Pliego}

En el sindicato cañero se dijo que el movimiento tiende al logro de varios objetivos. Informan que se ha presentado un pliego de peticiones con cuatro puntos:

1. Aumento de salarios por no menos del 15 por ciento.

2. Pago de 50 céntimos por cada metro lineal cortado de caña.

3. Discusión y resolución de un pliego de peticiones que contiene otros puntos, además de los citados.

4. Que no haya represalias. 
El contenido de este pliego se hizo circular ayer profusamente entre los trabajadores y fue entregado a los representantes de la empresa, en una reunión efectuada anoche.

\section{- La República, "Solucionada crisis en la Central Azucarera", 10 de marzo de 1979, 2.}

El vicepresidente de CODESA Adrián Hidalgo informó ayer que los trabajadores podrán reintegrarse a sus labores a las horas de costumbre, una vez que la guardia civil realizó la operación de eliminar los piquetes de sindicalistas que impedían el libre acceso a la Central Azucarera del Tempisque (CATSA).

Como resultado de esa acción, la guardia civil detuvo a 6 dirigentes sindicales, quienes no tienen ninguna relación con la empresa.

\section{HUELGA ILEGAL}

El Juez de Liberia, Lic. Marco Tulio González, declaró ilegal la huelga que mantuvieron los trabajadores de CATSA durante tres días. Entre las principales razones del fallo del Lic. González, están la de que los trabajadores no cumplieron los trámites legales previos a la declaratoria de huelga, tal y como lo señala el artículo 366 del Código de Trabajo. Así también de que se trata de labores agrícolas y de elaboración de los mismos, y siendo indispensable el funcionamiento de las empresas, al interrumpir las labores se causa un daño grave a la economía pública.

\section{INSTAN A LOS TRABAJADORES}

Los personeros de CATSA instaron a todos sus trabajadores para que reanuden sus labores a partir de hoy a las horas de costumbre.

Les comunicaron que al declararse ilegal el movimiento de huelga, las autoridades les brindarán toda la protección personal que sea necesaria para su reintegro a las labores, preservando su derecho inalienable al trabajo.

La empresa sigue anuente a dialogar con los trabajadores, siempre que se depusiera el estado de huelga. Y que se garantice que los dirigentes sindicales realmente representan a los trabajadores, pues el Sindicato de Trabajadores de la Caña (SITRACAÑA) no aparece inscrito en el Ministerio de Trabajo, según informó el presidente de CATSA Rolando Montoya.

\section{- La República, "Los sindicalistas mantienen estado de huelga en CAT- SA", 11 de marzo de 1979, 2.}

Mientras personeros de la Central Azucarera del Tempisque (CATSA) afirman que la huelga ha terminado y la mayoría de los trabajadores se incorporaron a sus labores ayer, dirigentes sindicales afirman que mantendrán el estado de huelga hasta tanto la empresa no negocie las garantías solicitadas por sus 
empleados. Así lo manifestó el dirigente del Sindicato Industrial Agrícola y de Plantaciones de Guanacaste (SITAPGUA) Ramón Villarreal. Además, el dirigente sindical Rodrigo Paniagua y el diputado Humberto Vargas Carbonell se trasladaron a la zona para apoyar a los trabajadores.

El Presidente Ejecutivo de CATSA Rolando Montoya dijo que el movimiento huelguístico había sido impuesto por un grupo pequeño de trabajadores, muchos de ellos ajenos a la empresa y negó la existencia de un sindicato en la misma. Por otra parte, el Ministro de Seguridad Pública Juan José Echeverría Brealey dijo que "hemos podido comprobar la presencia de agitadores entre los trabajadores dedicados a subvertir el orden de esa central azucarera".

\section{CONATO DE VIOLENCIA}

En horas de la madrugada de ayer un grupo de huelguistas que permanecía en una de las vías de acceso al ingenio de CATSA, cerca del puente de hamaca, apedreó a la guardia civil agrediendo a uno de ellos a machetazos, al sargento Antonio Castrillo, según se informó a La República.

El sargento Castrillo salió ileso y el resto de huelguistas se dispersó sin que se produjeran otros brotes de violencia. De acuerdo con las informaciones recibidas el agresor no fue detenido porque se dio a la fuga, pero en esta acción la guardia civil arrestó a 17 nicaragüenses sin documentación que se habían sumado al movimiento huelguístico.

El ministro Echeverría Brealey desmintió ayer que el personal asignado a la "operación Jaque Mate" fuera movilizado hacia la Central Azucarera. Y añadió que la fuerza pública está capacitada para que se respete el orden y "estamos dispuestos a que se cumpla la ley", toda vez que la huelga ha sido declarada ilegal.

Dijo no estar enterado del número exacto de detenidos durante la toma por la fuerza de esa empresa. Sin embargo, el asesor legal de Seguridad Lic. José Francisco Peralta presentó acusación en los tribunales de Liberia contra varios detenidos involucrados en la huelga de trabajadores de CATSA.

\section{ANEP CONDENA AGRESIÓN}

En un mensaje al Ministro Echeverría Brealey la Asociación Nacional de Empleados Públicos (ANEP) condena la agresión que están sufriendo los trabajadores de CATSA y sus dirigentes sindicales. "Esto contrasta claramente con el llamado al diálogo nacional que está haciendo el Gobierno, del cual usted es uno de los principales impulsadores", agregan.

Piden que cese todo tipo de represión, que se libre inmediatamente a los trabajadores encarcelados y que se promuevan de inmediato las negociaciones entre la empresa y los representantes de los trabajadores. 


\section{SE NORMALIZAN LABORES}

El superintendente de campo de CATSA, Roberto Castro, dijo que durante el día de ayer se habían normalizado las actividades de transporte, siembra, oficinas, talleres del ingenio, liberación de terrenos y riego. Agregó que la mayoría de trabajadores habían reanudado sus labores y que para el lunes esperaban que se normalizaran completamente las actividades del ingenio.

- La Prensa Libre, "Estudiantes se suman al paro del Tempisque. Colegio y escuelas de Filadelfia y Santa Ana", 13 de marzo de 1979, 2.

Dirigentes del Sindicato de Trabajadores de la Caña (SITRACAÑA) aseguraron hoy, en horas de la mañana, que la huelga declarada el miércoles pasado en la Central Azucarera del Tempisque S.A. (CATSA), continúa con mayor vigor que antes, al haberse sumado al paro, el Colegio de Filadelfia y tres escuelas de la misma localidad, así como una escuela de Santa Ana, Nicoya, apoyando a los trabajadores cañeros.

Dirigentes del Sindicato de Trabajadores Agrícolas de Guanacaste y de la Confederación General de Trabajadores manifestaron su decisión de ayudar a la solución de la huelga, "siempre que la empresa se manifieste dispuesta a celebrar reuniones en las que garantice la solución de solicitudes mínimas que demandan los trabajadores de Tempisque".

En las peticiones de los trabajadores están un 15 por ciento de aumento en los salarios y 0.50 centavos de colón por cada metro lineal de caña cortada.

Aunque la empresa sostiene que los trabajadores en su mayoría han vuelto a sus labores, los trabajadores insisten en que más del 95 por ciento están en huelga y que no la levantarán mientras no se dé solución a sus planteamientos.

Se espera para hoy una reunión con los funcionarios de la empresa. El paro afecta a 2.290 trabajadores, según la planilla del mes de febrero pasado, aunque la empresa dice que normalmente llegan a 1.500 solamente.

\section{INCIDENTES}

En el día de ayer ocurrieron los primeros incidentes serios en la huelga de CATSA. Un grupo de huelguistas interceptó a un autobús que transportaba aproximadamente a 100 trabajadores que se dirigían a sus labores en el ingenio, obligando a la intervención de las autoridades.

Por otra parte, cerca de 400 empleados de la Central Azucarera que se dirigían al ingenio para protestar por el fallo de ilegalidad de la huelga que dictó el juez local, se enfrentaron a un pelotón de la Guardia Civil que tuvo que usar gases lacrimógenos para dispersar a los manifestantes. 


\section{- La República, "Incertidumbre en CATSA", 14 de marzo de 1979, 2.}

El Gobierno designó al señor Carlos Ramírez, como mediador entre los trabajadores y la empresa CATSA, para buscar una solución a un conflicto que afecta la central azucarera, ubicada en Guardia de Liberia.

Ramírez, en una breve declaración que hizo ayer, manifestó que el 50\% de los trabajadores se encuentra ejecutando sus respectivas tareas en el ingenio.

Las labores en la Central Azucarera del Tempisque (CATSA) continúan normalmente, a pesar de que a algunos de los trabajadores dedicados a la corta de caña se les ha impedido el ingreso a sus lugares de trabajo, informó el vicepresidente de la empresa Raúl Oquendo.

Informó que un grupo de personas nuevamente impidió la entrada de los buses y pick-ups que trasladaban a estos trabajadores al ingenio, en la carretera que va a Santa Cruz y Nicoya.

El Tribunal Superior de Trabajo, además, aprobó por unanimidad la ilegalidad de la huelga, tal y como lo planteó el Juez de Liberia, Lic. Marco Tulio González. Y se informó que se dio orden a las autoridades para que garanticen la continuación de las labores.

Por su parte, la Ministra de Trabajo Lic. Estela Quesada dijo que las actividades del ingenio se habían normalizado, y que el movimiento solo fue un acto de perturbación del orden público.

Agregó que después de terminado este movimiento lo único que queda es un saldo de pérdidas por cientos de miles de colones, en una empresa que recién ha iniciado sus labores, y siendo esta la primera zafra que tienen. Afirmó que de acuerdo con los informes recibidos, siguen existiendo buenas relaciones entre la empresa y sus trabajadores.

Entretanto, los sindicalistas comunicaron ayer que en una asamblea general los trabajadores habían decidido no levantar el estado de huelga hasta tanto se conceda la liberación de los presos, el retiro de la Guardia Civil, y mejores salarios para los cortadores de caña. Sobre esta base empezarían a negociar el aumento salarial del $15 \%$ para todos los trabajadores y otras garantías laborales.

Informaron también que los dirigentes sindicales José Fabio Araya, de ANEP, y Rodrigo Paniagua, de la CGT, habían sostenido una reunión con el Ministro de Seguridad Johnny Echeverría Brealey para buscar un entendimiento entre las partes.

Por último, manifestaron que los estudiantes de secundaria del colegio de Filadelfia se unirían al paro de labores en apoyo a los trabajadores. 


\section{- La Prensa Libre, "Violencia ayer: choques e incertidumbre en el Tem- pisque", 17 de marzo de 1979, 2.}

Se acrecienta la incertidumbre en la zona llamada Paso del Tempisque, donde se han concentrado 250 trabajadores de la Central Azucarera Tempisque S.A. (CATSA), luego del paro de labores iniciado el pasado miércoles 7 de este mes.

Los dirigentes sindicales de FETRACAÑA afirman que los demás obreros se mantienen en huelga en las diferentes regiones donde viven y que en ellas han constituido comités de huelga. Aseveran que más del 90 por ciento de los trabajadores no acuden a sus labores desde que se declaró el paro de labores. En respaldo de sus afirmaciones informan que la caña cortada no alcanza para dar la presión adecuada a las calderas.

Informes provenientes del mismo sector laboral manifiestan que ayer se produjeron varios choques entre la Fuerza Pública y los trabajadores, en los que los encargados de mantener el orden público hicieron uso de gases antimotines para reducir la resistencia de los obreros. Aseveran que muchas personas, incluyendo ancianos y niños fueron afectados.

Para hoy se anuncia una reunión de trabajadores en el Paso del Tempisque, a la que se sumará una caravana de estudiantes y obreros que partirá de San José.

Mientras tanto funcionarios de la empresa sostienen que no negociarán con delegados que no representan a los trabajadores y que han sido calificados como "agitadores políticos de tendencia comunista". Reiteran los funcionarios de CATSA que la mayoría de los "auténticos obreros" están trabajando y que solo un pequeño grupo no ha podido retornar a sus labores porque ha sido impedido por piquetes de "agitadores".

\section{- La Prensa Libre, "Editorial: Agitación y subversión: rumbo que debe evitarse", 17 de marzo de 1979, 10.}

Continúa el país siendo escenario de conflictos laborales, si es que puede darse este último calificativo, a los brotes de violencia y al relativo estado de huelga que afecta a las plantas de "Central Azucarera Tempisque S.A."-CATSAla conocida empresa estatal, subsidiaria de CODESA.

Casi podría decirse que dudamos de seguir comentando estos problemas laborales o pseudolaborales, pues cerca está la fecha en que ciertos agitadores profesionales -bien conocidos por su falta de ingenio y originalidad- nos etiqueten con los consabidos epítetos de "anti-obreros", "anti-trabajadores" y "anti-sindicales".

Pero pensamos que Costa Rica exige un sacrificio más de sus hijos. No podemos catalogarnos de pueblos perfectos, y muchos de nuestros hermanos continúan padeciendo hambre y viviendo en condiciones no aceptables. Sin embargo, nuestro sistema depara muchas ventajas y evoluciona, de manera pacífica, hacia una mayor justicia; lo que amerita su defensa y perfeccionamientos, 
en aras de evitar el derramamiento de sangre, insensato y hasta cobarde, que unos pocos, con mala fe o por ignorancia, pretenden.

Somos fervientes partidarios de que los trabajadores sepan y logren defender sus derechos. Es justo que tengan un nivel de vida acorde con su esfuerzo. Mas no podemos ver con buenos ojos, que se siga violando el régimen jurídico, a vista y paciencia de los ciudadanos y-lo que es peor-con la tolerancia o acuerdo de personas o medios de comunicación, mal intencionados o tontos.

La actitud que el Ministerio de Trabajo y, especialmente su titular, la Lic. Estela Quesada, han tenido ante estos conflictos, es digno de mencionarse. Muchos la han calificado de pose extremista o estúpida. Mas ellos son quienes se dejan llevar por "la moda", creyendo buenas intenciones en personas que están -al menos en nivel de dirigencia- totalmente alejadas de este tipo de actitudes.

El país está siendo llevado a una época de agitación y subversión. Unos cuantos interesados, debidamente financiados por fuerzas ajenas a nuestra idiosincrasia, han logrado aprovecharse de causas justas, para enderezar la lucha con fines políticos, totalmente independientes, e incluso, hasta contrarios, a los que animan a los trabajadores perjudicados. Y ya no importa que la causa sea justa. Aun siendo injusta, se actúa, no solo por medio del convencimiento. Poco importa tener que usar la fuerza o los comportamientos terroristas.

Doña Estela Quesada tiene una virtud digna de destacar: es valiente. No tiene pelos en la lengua, para usar expresiones populares. No vive pensando en la posibilidad de ser electa para algún cargo. Más que política, doña Estela es una mujer decidida a defender lo que piensa.

La ingenuidad es a veces peor defecto que la maldad. En la segunda el actor sabe a dónde va. En la primera se puede dejar llevar por circunstancias o sentimentalismos. Quiera Dios que los costarricenses no pequemos de ingenuos y sepamos comprender - como ya lo ha hecho una buena mayoría- el valor y la verdad que encierra la denuncia de una mujer que, pudiendo descansar al alero del fruto de su esfuerzo profesional, -y no político- ha sabido ofrecer a la Patria un sacrificio más.

Doña Estela ha denunciado la verdadera situación de CATSA. Una denuncia, que, aun cuando dudáramos de su palabra, se confirmaría en la especial situación que ha tenido tal movimiento. El gobierno y el país deben cerrar filas con doña Estela.

Lamentamos profundamente que el señor Ministro de Seguridad Pública -según informes de un colega- haya decidido aceptar un pliego de peticiones propuesto por los actores de la agitación y haya decidido someterlo a la consideración del Poder Ejecutivo. En nuestro criterio, la conducta correcta era negarse a aceptarlo o, en su defecto, inmediatamente ponerlo en manos del despacho de la señora Ministra, lo cual no se había hecho al terminar el pasado jueves. 
O apoyamos el respeto al régimen jurídico y político que señala doña Estela, o tendremos que llorar mucho, no por perder bienes materiales, en definitiva intrascendentes, sino por vernos privados de la libertad que hasta hoy hemos disfrutado.

\section{- La República, "Editorial: El caso de CATSA", 17 de marzo de 1979, 8.}

Las situaciones anormales que están ocurriendo en la Central Azucarera del Tempisque (CATSA) caen bajo la responsabilidad directa de los agitadores profesionales extremistas y del Ministerio de Seguridad Pública.

Es inconcebible que la policía haya sido incapaz de garantizar a los trabajadores de la empresa azucarera el libre acceso a su centro de trabajo, y a los ciudadanos la seguridad en el tránsito por las carreteras nacionales.

Hemos comprobado que pequeños grupos de exaltados, en su mayoría jovencitos capitaneados por bien conocidos perturbadores de profesión, obligan en las carreteras a los vehículos particulares, cuyos conductores nada tienen que ver con el problema, a detenerse para exigirles una contribución en beneficio de los que se presentan disfrazados de huelguistas y si no acceden a esas demandas, los apedrean, sin que haya autoridades que impidan el desafuero.

Así, la presencia de los bullidores, en su casi totalidad ajenos a la empresa, y la sospechosa actitud de las autoridades, han provocado un caos peligroso, que debe cesar de forma inmediata.

Al Ministerio de Seguridad Pública no le corresponde otra cosa en el conflicto que garantizar el orden, hacer respetar las leyes, y dar a los trabajadores que quieran laborar la seguridad de que podrán hacerlo sin recibir perturbación alguna, y proceder así es su deber ineludible.

Llama la atención que mientras los agitadores de oficio gozan de la incapacidad de las autoridades por controlar sus desmanes, canalizan las peticiones económico-sociales que hacen para encubrir su subversión a través del Despacho de Seguridad Pública, en actitud que sugiere la existencia del afán de poner un confite en la boca de su titular, al que endulzan con la perspectiva de que por su medio se logrará una solución al problema, para restarle bríos en el cumplimiento de sus deberes.

Recordamos el caso reciente de "La Teresa" en el que una pseudohuelga, montada desde fuera de la empresa con la participación de los mismos personajes que ahora están en guardia en la primera línea, fracasó porque esa vez las autoridades adoptaron la actitud enérgica que les corresponde, pero parece que no se aprendió aquella lección.

Si se tolera que los agitadores profesionales anden de empresa en empresa a todo lo largo y ancho del país, impidiendo por la fuerza que los trabajadores de ellas presten sus labores, y se permite que actos subversivos de esa naturaleza 
pase como "huelgas laborales", seremos los responsables directos de haber caído en la subversión comunista.

Bien hace CATSA en negarse terminantemente a negociar con quienes nada tienen que ver con la empresa. Trate ella con sus trabajadores, pero no le haga daño a Costa Rica de otorgar credenciales de legitimidad a quienes hace tres semanas estaban agitando en los bananales del sur y hoy aparecen agitando en los cañales del norte.

\section{- Mario Sancho, Secretario de SITRACAÑA, "De SITRACAÑA a la Opinión Pública", La Prensa Libre, 21 de marzo de 1979, 9.}

Por espacio de trece días los obreros cañeros del Tempisque nos mantuvimos en huelga. En estos trece días, ricos en combatividad y firmeza, se logró arrancar a la empresa C.A.T.S.A. las reivindicaciones contenidas en el pliego mínimo levantado por los trabajadores.

1. Aumento de los pagos en el corte de caña con base en la siguiente tarifa: $£ 0.20$ por metro lineal en los cortes extraordinariamente ralos, 0.30 por metro lineal en los cortes medianos y 0.40 por metro lineal en los cortes densos.

2. Compromiso de no ejercer ningún tipo de represalias contra los obreros que se mantuvieron en huelga.

3. Garantías de la más plena libertad sindical.

4. Reintegro a sus labores de los obreros injustamente despedidos.

5. Aumento salarial para los obreros que ganan por hora.

6. Realización de una Asamblea General que elija a los legítimos representantes para negociar con la empresa todos los asuntos que interesen a los obreros y en especial el pliego de peticiones presentado por S.I.T.R.A.C.A.Ñ.A.

En esta lucha, la más importante librada por los trabajadores guanacastecos, fue decisivo el formidable apoyo de las comunidades y del estudiantado de la zona. Hechos que enaltecen a las mujeres, a los estudiantes y a los obreros guanacastecos, se dieron a diario.

Para consolidar definitivamente la victoria alcanzada, S.I.T.R.A.C.A.Ñ.A. considera necesaria la realización de una Asamblea General de los trabajadores de C.A.T.S.A., que tenga como principal objetivo elegir a los delegados obreros que negociarán con la empresa el pliego de peticiones presentado. En esa Asamblea se demostrará ante todo el país quién es el legítimo representante de los trabajadores: si el grupo de empleados de confianza de la empresa o S.I.T.R.A.C.A. Ñ.A. Así se echarán por tierra todas las maniobras divisionistas y las mentiras de los extranjeros que mal manejan C.A.T.S.A. Los mecanismos de la Asamblea 
deben ser fijados de común acuerdo entre el árbitro nombrado por el Gobierno y los trabajadores, de manera que se garantice la más completa participación y democracia.

Los obreros afiliados a S.I.T.R.A.C.A.Ñ.A. reunidos en Asamblea General en la iglesia de Paso Tempisque, la noche del 19 de marzo de 1979, resolvimos suspender el estado de huelga a partir del día 20 de marzo de 1979. Así demostramos una vez más, nuestra disposición al diálogo y a la negociación, reservándonos, eso sí, el derecho de reiniciar la huelga si en un plazo de ocho días los compromisos adquiridos por la parte patronal, no son cumplidos.

\section{SINDICATO DE TRABAJADORES DE LA CAÑA}

Mario Sancho Barrantes

Secretario General

- La Prensa Libre, "Paro ayer en CATSA. No pagaron quincena", 22 de marzo de 1979, 3.

Más de sesenta trabajadores del ingenio y de construcciones de la Central Azucarera Tempisque S.A. (CATSA), suspendieron labores ayer en protesta por la falta de pago de salarios correspondientes a la quincena pasada, según informes llegados de la zona.

Los dirigentes del Sindicato de Trabajadores de la Caña (SITRACAÑA) denunciaron violaciones por parte del CATSA, a los acuerdos suscritos entre los trabajadores y el Gobierno de la República y aceptados por la empresa.

Los dirigentes sindicales sostienen que los despedidos hasta ahora ascienden a diez, entre ellos varios dirigentes sindicales.

El Secretario General de SITRACAÑA, señor Mario Sancho, aseguró que si hoy no son restituidos en sus puestos los trabajadores "injustamente despedidos" y no se pagan los salarios a los del ingenio y de la construcción, la huelga será nuevamente declarada y que esta vez tendrá consecuencias imprevisibles.

\section{COMPAÑÍA AZUCARERA SOSTIENE QUE NO HUBO PARO EN EL INGENIO}

Por su parte, el ingeniero Fernán Peralta, Administrador Residente de CATSA, afirma que no han violado ningún acuerdo y que en el caso de los trabajadores despedidos por diversos motivos, solo esperan la presencia del Interventor nombrado por el Gobierno, para que sea él quien determine cuáles trabajadores podrán ser restituidos en sus labores luego de un análisis caso por caso.

Negó que se hubiera producido un paro interno de labores en el ingenio ayer, manifestando que el atraso en el pago de salarios a unas cuantas personas obedecía a razones de administración y a ciertas anormalidades involuntariamente 
producidas, pero comprensibles si se considera que la empresa tuvo varios días de "semihuelga".

Reiteró que los trabajos en el ingenio, las construcciones, los riegos, plantaciones y la corta de la caña, se realizan normalmente. En este último caso, dijo que la afluencia de cortadores de caña se había incrementado con la normalización en los transportes.

- CATSA, "Junta Directiva de CATSA fija su posición”, La Prensa Libre, 22 de marzo de 1979, 11.

\section{Acuerdo unánime de Sesión No $148-79$ del 20 de marzo de 1979}

1. Que en CATSA ha habido una huelga política que se ha tratado de imponer a los trabajadores.

2. Que hemos seguido laborando a pesar de las amenazas a nuestros obreros, técnicos y funcionarios.

3. Que no hemos negociado ni nunca negociaremos con elementos foráneos, que se arrogan la representación de nuestros trabajadores.

4. Que como reconocimiento a la lealtad de nuestros genuinos trabajadores que han sido leales a la Empresa y a la Democracia Costarricense hemos concretado un acuerdo con ellos, que les otorga beneficios adicionales y en especial a los cortadores de caña que ahora convienen previamente y conjuntamente con representantes de la Empresa, el precio de la corta.

\section{Acuerdo unánime de Sesión No ${ }^{\circ}$ 149-79 del 21 de marzo de 1979}

1. Conscientes de que se ha actuado correctamente en esta administración y debido a ciertas manifestaciones tendenciosas se acuerda pedir a la Contraloría General de la República una revisión de todo lo actuado tanto por esta Administración como las anteriores.

2. Solicitar al señor Presidente de la República que no acepte la renuncia presentada por la Ministra de Trabajo, licencia Estela Quesada Hernández.

3. Indicar que solamente se aceptará un árbitro para que compruebe si los despidos que la empresa ha efectuado han sido hechos a derecho, respetando en todo momento los derechos de sus trabajadores.

- La Nación, "CATSA dice que no hay huelga; SITRACAÑA insiste en que sí", 30 de marzo de 1979, $4^{\text {a }}$.

Representantes del Sindicato de Trabajadores de la Caña (SITRACAÑA) afirmaron que ayer a las 5.30 a.m. se reinició la huelga de cortadores en el ingenio "Federico Sobrado Carrera", situado en Guardia de Liberia, Guanacaste. 
Sin embargo, el licenciado Rolando Montoya, presidente de la Central Azucarera Tempisque (CATSA), propietaria de dicho ingenio, negó la noticia y afirmó que todo transcurre normalmente en la producción azucarera.

\section{Situación}

Los dirigentes sindicales don Mario Sancho y don Rolando Barrantes informaron ayer a La Nación desde Paso Tempisque -lugar donde según ellos están concentrados los huelguistas-, que a las 5:30 a.m. se reinició el paro de labores en CATSA, "ante la actitud de la empresa de no querer negociar con el sindicato un pliego de peticiones presentado la semana pasada".

Dijeron que dada la situación de los trabajadores en cuanto a alimentación, se les instruyó para que permanezcan en sus casas, mientras un grupo, que dijeron suma 250 hombres, se mantiene en Paso Tempisque. La mayoría está en la ermita de la localidad.

Don Mario Sancho aseveró que "el ingenio está paralizado, porque el 95 por ciento de los trabajadores no se presentó a laborar en la corta de caña". El señor Sancho, al reaccionar, por comunicados que ha hecho circular la empresa en el sentido de que la situación es normal en CATSA y que no hay huelga, manifestó:

\footnotetext{
"Si es cierto que no hay huelga, ¿por qué tienen aquí 100 guardias civiles con equipo antimotín, acuartelados en este pueblo y sembrando el temor entre los vecinos?".

“¿Por qué si en CATSA no pasa nada, el gobierno persiste en la negativa para que los trabajadores se organicen mediante una asamblea general que no les ha permitido efectuar? De hecho, aquí pasó algo e invitamos a la prensa para que venga a constatarlo".
}

Por su parte, la regidora municipal de Carrillo, por el partido Unidad, doña Josefina Hernández, llamó ayer a La Nación para denunciar la presencia de un contingente de guardias civiles en Paso Tempisque.

Se quejó de que la autoridad mantiene una actitud amenazante, "no obstante -afirmó- que los trabajadores están en plan pasivo y rehúyen los hostigamientos de la policía".

Confirmó, "es cierto que hay huelga en CATSA" y ya se pidió toda la ayuda de los diputados, pues según dijo, "toda la población está rodeada por la guardia". Oficiales de la Comandancia de plaza de Liberia ratificaron que, un contingente de la Guardia Civil, provisto de equipo antimotín, se trasladó ayer a Paso Tempisque, para prevenir cualquier actividad que tienda a subvertir el orden.

Informaron, además, que hasta ese momento -horas de la tarde- no se había presentado ningún incidente. 


\section{CATSA niega}

Tanto el licenciado Rolando Montoya, como la Corporación Costarricense de Desarrollo (CODESA), de la que es subsidiaria la empresa azucarera, afirmaron que el ingenio labora normalmente y que no hay paro de actividades.

CODESA denunció que "los agitadores enviados a la zona, sin relación alguna con la empresa, pretenden crear una situación artificial y dan informaciones falsas, como esta de que los trabajadores de CATSA se declararon en huelga, cuando la realidad es que todos laboran responsablemente".

\section{- La República, "Cañeros exigen respuesta", 4 de abril de 1979, 5.}

Cientos de trabajadores de la Central Azucarera del Tempisque (CATSA) decidieron anoche permanecer frente a la Casa Presidencial, hasta tanto no reciban una respuesta del Gobierno que les garantice que no habrá represalias contra los trabajadores, el derecho a la sindicalización, el reintegro de trabajadores despedidos, la realización de la asamblea general y la negociación del pliego de peticiones.

Anoche habían instalado quince tiendas de campaña en el Parque Nacional. En principio, los trabajadores aceptaron la intervención del árbitro nombrado por el Presidente de la República, Lic. Rodrigo Carazo, para evaluar las relaciones obrero-patronales de esa empresa.

El primer mandatario, de acuerdo con un comunicado de prensa del 2 de abril, ya informó a la empresa que había nombrado como árbitro al señor Armando Sáenz Herrera, funcionario del Ministerio de Trabajo. Y ayer, el Ministro de la Presidencia, José Rafael Cordero Croceri, en nombre del Presidente, les comunicó este nombramiento a los delegados de los trabajadores de CATSA que se reunieron con él en horas de la tarde, para presentarle un pliego de peticiones para levantar el estado de huelga.

\section{Gran concentración de trabajadores}

Los trabajadores de CATSA desfilaron ayer en fila india desde la Estatua de León Cortés hasta la Casa Presidencial, para demostrar al Gobierno, según informaron, la veracidad de la huelga en la Central Azucarera con el fin de lograr mejoras salariales. A esta manifestación también se sumaron otros grupos brindándoles apoyo a estos trabajadores.

En las conversaciones con el ministro Cordero Croceri, el asesor legal del Sindicato de Trabajadores (SITRACAÑA), Otto Castro, le entregó el pliego de peticiones en el cual incluyeron el proyecto de convención colectiva, un documento donde rechazan el arreglo directo firmado entre el comité permanente de trabajadores de CATSA y la empresa; un análisis del porqué se retornó a la huelga; y los cinco puntos antes mencionados. 
El ministro Cordero Croceri, por su parte, les comunicó que el árbitro nombrado por el presidente Carazo tendría plenas facultades para estudiar y evaluar todos los problemas de despido de trabajadores, salarios, condiciones de trabajo y jornadas de los empleados de CATSA.

Los trabajadores demostraron recelo ante el nombramiento del señor Armando Sáenz Herrera como árbitro, por ser funcionario del Ministerio de Trabajo. Sin embargo, el ministro Cordero Croceri les manifestó que debían tener confianza en las decisiones del presidente Carazo, quien lo designó dado que Sáenz Herrera "posee una vasta experiencia en este campo y es una garantía de imparcialidad y objetividad, tanto para los trabajadores como para la empresa".

Entre otras cosas, los trabajadores denunciaron ante el ministro Cordero Croceri arbitrariedades cometidas por la Guardia Civil y los directivos de la empresa. En cuanto al primer punto, Cordero Croceri señaló que las autoridades únicamente han garantizado el libre derecho a trabajar.

Entretanto, hoy a las 10:00 a.m. se realizará una reunión de diputados para discutir los problemas de los trabajadores de CATSA.

\section{- La Prensa Libre, "La normalidad volvió a CATSA", 5 de abril de 1979, 2.}

Desde ayer, en horas de la noche, comenzaron a retornar a la zona del Tempisque los 600 trabajadores que el martes pasado salieron de esa localidad para concentrarse frente a la Casa Presidencial en demanda de soluciones a sus reclamos. Con el regreso de los últimos trabajadores al ingenio azucarero de Guardia, Guanacaste, se normalizaron hoy todas las actividades de la Central Azucarera Tempisque S.A., tanto en el ingenio como en los campos destinados a la siembra de la caña.

Los obreros que en principio objetaron al árbitro nombrado por el Gobierno aduciendo que era un funcionario incondicional de la Ministra de Trabajo, aceptaron finalmente su presencia para solucionar aspectos relativos a despidos, restituciones al trabajo, salarios, jornadas de labores y aumentos, así como para organizar próximamente una asamblea general de trabajadores para que sean ellos los que determinen si aceptan o no a SITRACAÑA como la entidad sindical que los represente en el futuro.

Por su parte, representantes de la empresa manifestaron su complacencia por que todo haya vuelto a la normalidad y que tanto el ingenio como las plantaciones, muestren ahora una fisionomía distinta a la de hace unos días, cuando la incertidumbre era la nota dominante en la zona. Aunque la empresa nunca reconoció la existencia de una huelga, no dejó de indicar que había un cierto ausentismo que finalmente ha quedado solucionado. 


\section{- CATSA, "En CATSA nunca hubo huelga", La República, 10 de abril de 1979, 7.}

La Junta Directiva reunida el 9 de abril de 1979 acordó en forma unánime dirigirse a la Ciudadanía para dar sus últimas declaraciones en relación con la crisis que provocaron personas ajenas a la Empresa.

Acuerdo:

PRIMERO: Señalar que el señor Presidente de la República nunca se reunió con el grupo que marchó por San José y luego permaneció frente a la Casa Presidencial y que pretendía representar a los trabajadores de CATSA.

SEGUNDO: Que ese grupo ha pretendido mostrar como un acuerdo con el señor Presidente, la oferta que CATSA hizo a todos sus trabajadores y que fue publicada en diferentes medios, a partir del 18 de marzo de 1979 y que en algunos puntos ofrecía:

5. "A garantizar, según lo establecido en nuestra legislación el derecho de la libre sindicalización".

6. "A no tomar represalias... y a la disposición de CATSA, a que un árbitro designado por el señor Presidente de la República estudie y analice todos y cada uno de los despidos efectuados y que reinstalará a su trabajo a aquellos que el mencionado árbitro considere acreedores a tal beneficio".

TERCERO: Prueba de que nunca ha habido huelga sino un quebrantamiento de las leyes, es la continua entrega a la Liga de la Caña, de azúcar producida en CATSA, así como al hecho de que después de las declaraciones de suspensión de huelga, de esos grupos ajenos a la Empresa, han seguido trabajando en CATSA el mismo número de trabajadores que antes de dicha suspensión.

CUARTO: Que las magníficas relaciones laborales que CATSA mantiene con sus trabajadores, mejoradas con el "ARREGLO DIRECTO" que realizó con los mismos, demuestran que el diálogo sincero es la forma más eficaz de lograr mutuos beneficios.

QUINTO: Que esta crisis provocada, culminó con el triunfo del derecho al trabajo, la paz, la concordia y el diálogo. El diálogo constructivo debe seguir siendo el medio que se utilice en Costa Rica, en lugar de aplicar sistemas de violencia ajenos a nuestra idiosincrasia, que solo conducen a generar pérdidas a todos los costarricenses.

JUNTA DIRECTIVA DE CATSA 
